\title{
Exploratory Laparatomy in a Schizophrenic Patient with Parasiticide as a High Risk Behavior; Ekbom Syndrome: A Case Report
}

\author{
Reza Bidaki, ${ }^{1,2,}$ Seyed Ali Mostafavi, ${ }^{3}$ and Ehsan Farhadi Shourbalaghi ${ }^{4}$ \\ ${ }^{1}$ Research Center of Addiction and Behavioral Sciences, Shahid Sadoughi University of Medical Sciences, Yazd, IR Iran \\ ${ }^{2}$ Diabetes Research Center, Shahid Sadoughi University of Medical Sciences, Yazd, IR Iran \\ ${ }^{3}$ Psychiatry and Psychology Research Center, Roozbeh Hospital, Tehran University of Medical Sciences, Tehran, IR Iran \\ ${ }^{4}$ Young Researchers and Elite Club, Yazd Branch, Islamic Azad University, Yazd, IR Iran \\ "Corresponding author: Reza Bidaki, Research Center of Addiction and Behavioral Sciences, Shahid Sadoughi University of Medical Sciences, Yazd, IR Iran. Tel/Fax: \\ +98-3532633555, E-mail: Reza_Bidaki@yahoo.com
}

Received 2015 May 19; Revised 2015 July 14; Accepted 2015 November 16.

\begin{abstract}
Introduction: Delusions of parasitosis or Ekbom syndrome are a psychotic disorder that causes a patient to suffer from the substantial false belief that he or she is infested with a parasite or helminth.

Case Presentation: The patient was a 44-year-old, unemployed divorced man with a past psychiatric history of schizophrenia. He was referred to the emergency department (ED) with a complaint of a rupture of the abdomen. He believed that a large, threatening helminth or macro parasite had entered in his abdomen and was eating and destroying his intestines, liver and other internal organs. Therefore, following these thoughts, he decided to explore his abdomen and to remove of this "vampire."

Conclusions: Delusional infestation or parasitosis may be detected in context and secondary to schizophrenia with nihilistic delusion and may create a high degree of suffering for patients, ultimately cause mortality, because of threatening behaviors toward the self.
\end{abstract}

Keywords: Ekbom Syndrome, Parasitosis, Schizophrenia, Delusions

\section{Introduction}

Delusory parasitosis, or delusional disorder / somatic type, is a psychotic disorder wherein a patient suffers from a substantial false belief that he or she is infested with a parasite (1). The symptoms appear slowly or violently. The patient may express pruritus, tactile hallucinations, or fornication $(2,3)$. The male-to-female occurrence ratio is $1: 1.5$, and the mean age of onset is nearly 57 years (1).

Self-damage without the will to die or self-mutilation may occur in borderline personality disorder, factitious disorder, and schizophrenia. It is more prevalent in female patients (4).

\section{Case Presentation}

The patient was a 44-year-old white, divorced, unemployed male, with low socio-economic status and a past psychiatric history of schizophrenia. He presented to the emergency department (ED) with complaints of a loss of consciousness and rupture of his abdomen. His medical condition was serious. The surgeon repaired his abdomen and internal organs, and after three weeks, he was referred to the psychiatric ward with partial improvement for treatment of his thoughts. In previous months, he believed that a large, threatening and invisible helminth, or macro parasite, had entered his abdomen and was eating and destroying his intestines, liver, and other internal organs. He was convinced it was growing. He said that he felt it under the skin of his abdomen, but could not see it. No one believed him. Therefore, he was confused and very angry and worried. He did not try to kill it using a paracidic agent, as he believed the parasite was huge and resistant to drugs or poisons. He was not a surgeon, but decided to use a knife to create a laceration and explore the inside of his abdomen, in hopes of removing this single Vampire worm. His surgery was conducted under non-sterile conditions in his home, and he seriously hurt himself (Figure 1).

The patient's medical history was negative, but psychiatric hospitalization and suicide attempts were positive in his past. A family history of psychiatric disorders was positive regarding his mother, who had depressive disorder, and his father, who was violent and depressive.

The patient's manner was non-cooperative and unpleasant, with mild psychomotor retardation. Speech was decreased by a poverty of thoughts, and perseveration was detected. His mood was described as depressed. His thought processes were tangential and illogical and he was positive for evidence of delusions and paranoia.

He was diagnosed with delusional disorder, somatic 


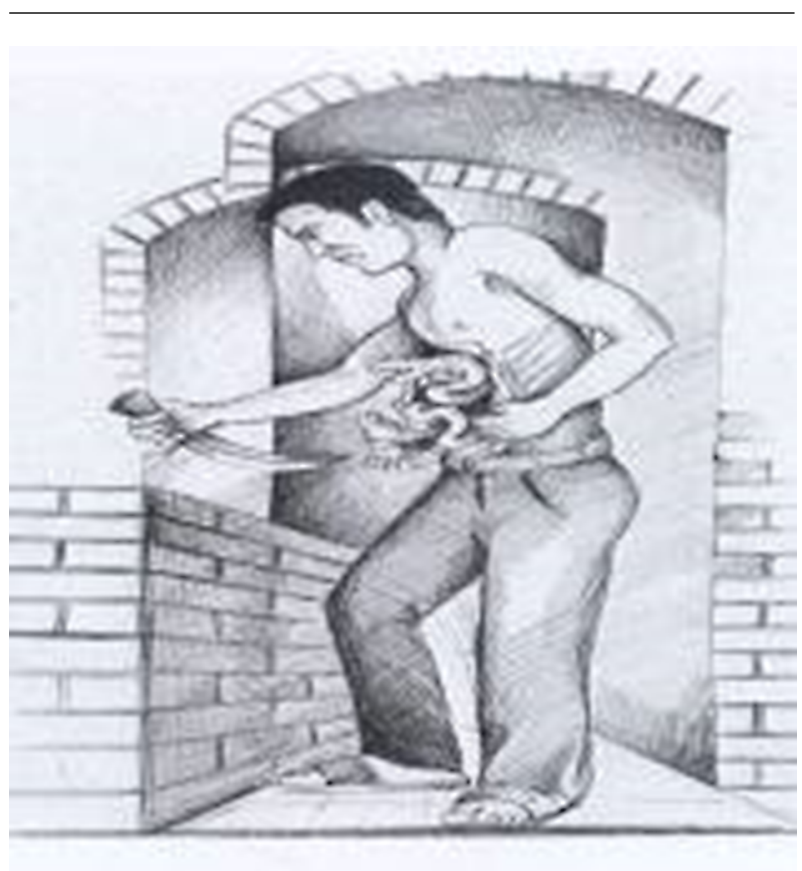

Figure 1. Ekbom Syndrome (Picture by Abdi)

type (known as Ekbom syndrome, or delusional parasitosis). We started one 2-mg tablet of Risperidone at bedtime for delusions of somatic type, and this was up-titrated to 4 $\mathrm{mg}$ at bedtime to optimally control his delusions. He also complained of depressive mood, which was first treated with a 50-mg tablet of Sertraline, and later increased to 100 $\mathrm{mg}$ / daily, along with $1 \mathrm{mg}$ Clonazepam at night and NaValproate $200 \mathrm{mg} / \mathrm{TDS}$. The hospitalization was long, due to his fixed delusions.

The patient's routine laboratory tests were intact, and the urine drug tests were negative. Neurological examination, electro encephalography, and magnetic resonance imaging (MRI) were intact.

After 39 days, the patient was discharged, but his symptoms were not omitted completely. He believed that the helminth was still in his abdomen. Of course, his delusions were remarkably decreased.

\section{Discussion}

Bouree and colleagues explain delusions of parasitosis, or Ekbom syndrome, as occurring mainly in pre-invasive senile women who are single or living alone (2). On the contrary, our case was a middle-aged divorced man. According to DSM-5, schizophrenia spectrum disorders are defined: "in one or more of the following five domains: delusions, hallucinations, disorganized thinking (speech), grossly disorganized or abnormal motor behavior (including catatonia), and negative symptoms" (5). So, according to the above signs and symptoms, the major diagnosis for this patient is schizophrenia; delusional disorder occurred in context of schizophrenia. Our case included bizarre behavior, disorganized speech (a poverty content of speech), and negative symptoms (impaired self-care, social isolation, abulia, alogia) for more than six months. His problems were not in the context of a general medical condition (GMC) or substance abuse. Therefore, the diagnosis of schizophrenia was definite. His delusion of parasitosis was one of the symptoms of this patient, in the context of a major disorder like schizophrenia.

A literature review revealed that cases such as these are reported as being only rarely life-threatening, but they are always life-altering for patients and their families $(3,4)$. The actions of this patient were odd, threatening bizarre, and uncommon. It was not a suicide attempt.

This man was going through a divorce and perhaps could not accept his wife's abandonment of him, so he redirected his focus to putative parasites in his internal organs. Therefore, the delusions of parasitosis may be an immature defense mechanism whereby the patient displaced or diverted the emotions with which he could not deal and substituted an infestation of obsessive thoughts (6).

The patient did not feel severe pain during his act. As some previous studies have indicated, patients with schizophrenia are not sensitive to much somatic pain associated with illness and injuries (7). Because no one agreed with him about this crisis, perhaps the patient's self-harm was a cry for help from this patient

We also found a report from eastern Asia of a schizophrenic patient had cut his genital system because of assumed necrosis (8). Of course, the behavior of our patient was more dangerous, bizarre and adventuresome, as he believed he was fighting an aggressive and living foreign body.

Drug non-compliance, poor response to nonpsychiatric treatment, and significant distress may lead to secondary depressive states. Suitable rapport, empathic, and supportive therapy and declines in the high expression of emotional conditions in a family setting are effective approaches for dealing with these patients $(9,10)$. Concerning this case, the level of family support was poor, and there was a high expression of emotion within his family. His judgment and sense of reality were impaired, and he did not accept his problems as indicative of a disorder.

It is an obsessive phobic state in which a person thinks, believes, or even imagines that he or she is involved with parasites. Therefore, this is an ego-dystonic condition where in the patient has a preoccupation with his or her 
thoughts. The laceration of the abdomen can be seen as a compulsive behavior in reply to these obsessions.

Our patient also believed that the parasite had eaten and destroyed part of his heart, stomach, intestines, and liver. Therefore, nihilistic delusion was another sign present in this schizophrenic patient.

This is a rare report about an odd and bizarre behavior in the context of delusional infestation. The condition could have caused mortality, because of the patient's threatening behavior toward himself.

\section{Acknowledgments}

We thank the staff of the Iran psychiatry hospital, in Tehran, for its suitable provision of nursing care to this patient.

\section{Footnote}

Authors' Contribution: Reza Bidaki: study concept and design, acquisition of data, interpretation of data, drafting the article, critical revision of the article, final approval of the version to be published participated;SeyedAli Mostafavi: interpretation of data, drafting the article, critical revision of the article, final approval of the version to be published participated; Ehsan Farhadi Shourbolaghi: acquisition of data, drafting the article, final approval of the version to be published participated.

\section{References}

1. Zomer SF, De Wit RF, Van Bronswijk JE, Nabarro G, Van Vloten WA. Delusions of parasitosis. A psychiatric disorder to be treated by dermatologists? An analysis of 33 patients. Br J Dermatol. 1998;138(6):1030-2. [PubMed: 9747367].

2. Larsson CE OM, Balda AC. Delirio de parasitose (Acarofobia): relato de caso em Sao Paulo (Brasil). Bras Dermatol. 2000;75:723-8.

3. Koo J, Lee CS. Delusions of parasitosis. A dermatologist's guide to diagnosis and treatment. Am J Clin Dermatol. 2001;2(5):285-90. [PubMed: 11721647].

4. Langbehn DR, Pfohl B. Clinical correlates of self-mutilation among psychiatric inpatients. Ann Clin Psychiatry. 1993;5(1):45-51. [PubMed: 8348198].

5. American-Psychiatric-Association . Schizophrenia spectrum and other psychotic disorders. 2014

6. Bouree P, Benattar B, Perivier S. [Ekbom syndrome or delusional parasitosis]. Rev Prat. 2007;57(6):585-9. [PubMed:17593780].

7. Dworkin RH. Pain insensitivity in schizophrenia: a neglected phenomenon and some implications. Schizophr Bull. 1994;20(2):235-48. [PubMed: 8085127].

8. Mitsui K, Kokubo H, Kato K, Nakamura K, Aoki S, Taki T, et al. [A case of self-mutilation of testis]. Hinyokika Kiyo. 2002;48(5):281-3. [PubMed: 12094710].

9. Healy R, Taylor R, Dhoat S, Leschynska E, Bewley AP. Management of patients with delusional parasitosis in a joint dermatology/ liaison psychiatry clinic. Br J Dermatol. 2009;161(1):197-9. doi: 10.1111/j.13652133.2009.09183.x. [PubMed:19438458].

10. Bourgeois ML, Duhamel P, Verdoux H. Delusional parasitosis: folie a deux and attempted murder of a family doctor. Br J Psychiatry. 1992;161:709-11. [PubMed: 1422627]. 